\title{
CONSTRUCCIÓN DISCURSIVA DE LA MISMIDAD Y DE LA OTREDAD EN EL DISCURSO POÉTICO Y VISUAL MAPUCHE ${ }^{1}$
}

\author{
SONIA BETANCOUR SÁNCHEZ \\ Universidad de La Frontera
}

\section{Resumen}

El arte poético de Leonel Lienlaf y el arte visual de Juan Silva Painequeo se hallan vinculados a la historia conflictuada con la sociedad global, lo que orienta los significados de estas expresiones artísticas en las que, a partir de las relaciones con la sociedad occidental, el sujeto del discurso afianza su identidad.

Este trabajo observa el diálogo entre la mismidad y la otredad del sujeto y el proceso de construcción de las mismas en el arte poético y visual mapuche de estos dos creadores, con el propósito de evidenciar funciones y significados del discurso en la configuración del sujeto cultural.

Palabras clave: Arte poético, Arte visual, Otredad, Mismidad, Sujeto, Identidad.

Abstract

The poetic art of Leonel Lienlaf and the visual art Juan Pablo Silva Painequeo are tied together by history of a conflict with global society. This fact guides their artistic expressions through which they strengthen their ethnic identity.

The present paper observes the dialog between the self and the different one in the building process of their particular Mapuche art - poetic and visual in order to make evident the meaning and functions of their discourse in the shaping of the cultural subject.

Key words: Arts poetic, Visual art; the different one; the self; cultural subject; identity.

${ }^{1}$ El presente trabajo forma parte del Proyecto DIUFRO D-107-0005, “La dinámica estéticocultural del actual discurso artístico mapuche: aproximaciones a las relación entre poesía y visualidad", cuyo equipo de trabajo está formado por la Investigadora Responsable, profesora Mabel García Barrera y los co-investigadores Hugo Carrasco Muñoz y Sonia Betancour Sánchez. Parte de este trabajo fue presentada por su autora en el Congreso FLACSO, Ecuador, 2007, con la ponencia "La construcción del sujeto cultural en el discurso y metadiscurso poético y visual mapuche". 


\section{Introducción}

$\mathrm{E}$ 1 pueblo mapuche en Chile tiene una historia de conflictos y de convivencia forzada con la cultura mayoritaria, la cual ha marcado las relaciones entre ambas culturas, siempre conflictuadas $\mathrm{y}$, desde esta tensión, el sujeto cultural propone espacios de expresión a través de sus producciones artísticas, desde donde reflexiona su historia, su cultura, su propio ser cultural.

Inicialmente fueron producciones que asumían las formas tradicionales de la cultura propia y, luego, influidos por el contacto intercultural, fueron acogiendo y transformando elementos de la cultura occidental (Bonfil, 1989), dando origen a expresiones artísticas con características notoriamente híbridas - formas discursivas en poesía, materiales y técnicas pictóricas en el arte visual, por ejemplo - y, a la vez, han mantenido formas de arte tradicionales - como textilería, el uso del cuero en pintura - (García, Carrasco, Contreras, 2005).

El artista mapuche vive un proceso de toma de conciencia de su identidad cultural (Carrasco, 2002), o quizás más claramente, un proceso de afianzamiento de la misma y en sus variadas producciones artísticas textualizan esta línea temática que normalmente se halla relacionada con la dominación que ha ejercido la cultura mayoritaria respecto de la cultura mapuche pero, sobre todo, expresa la cultura ancestral, su sistema de creencias, su identidad cultural.

Desde estas vivencias y desde los elementos culturales- lengua, religión, sistema mítico-creencial, cultura ancestral que los contiene y define, como desde las experienciadas en el contacto con la cultura ajena que han puesto en peligro esos elementos culturales- construye un discurso expresado y contenido en un proyecto artístico que da cuenta de esta realidad pero que, al mismo tiempo, está al servicio de una reafirmación de la identidad cultural.

En este sentido, sostengo que tanto el discurso poético de Leonel Lienlaf como el discurso visual de Juan Silva Painequeo ${ }^{2}$ constituyen la textualización de la construcción de la mismidad del sujeto $\mathrm{y}$, simultáneamente, la construcción de la otredad del mismo, una otredad compleja que necesita ser definida para re-conciliarse con la mismidad de aquél.

Sobre la diferencia cultural dice Bhabha (2002), ésta no se debe entender en una línea de disputas entre contenidos que se oponen; su objetivo sería la rearticulación de conocimientos desde una mirada distinta, la mirada de la minoría y, en este sentido, el sujeto del discurso de la diferencia cultural es un sujeto dialógico; es en esta línea donde situamos la mirada sobre la poesía de Leonel Lienlaf en Se ha despertado el ave de mi corazón y en la obra visual de Juan Silva Painequeo.

\footnotetext{
${ }^{2}$ Las obras incluidas en este trabajo como corpus de análisis, fueron especialmente autorizadas por este artista visual para su estudio en esta investigación.
} 


\section{Sujeto y discurso}

El discurso revela la existencia de un sujeto - mapuche - en conflicto con otro - no mapuche - conflicto fundado en la relación colonizado/colonizador que el discurso se encarga de evidenciar y un sujeto mapuche que resiente en él la convivencia de ambos, que se debate entre lo propio - mapuche - y lo ajeno no mapuche - causante este último de una especie de escisión que lo angustia, que le reclama una reflexión profunda sobre su ser cultural, que le exige resignificarse, re-definirse en el discurso, todo con lo cual dialoga en un espacio textual donde el conflicto y la tensión del sujeto escindido se deben resolver, en el re-conocimiento y re-encuentro de su ser cultural con el que se reconcilia y entra en comunión para afianzar su identidad de sujeto mapuche y, en esta certeza, enfrentar discursivamente al otro cultural.

La expresión del yo es la expresión de la subjetividad, lo que, en definitiva, responde a la expresión de un sujeto o voz colectiva como en el discurso visual de Silva Painequeo, donde la identificación del yo con el colectivo cultural se expresa significativamente en la expresión de elementos identitarios como el sistema creencial, el sistema administrativo y también en la expresión de las relaciones tensionadas con la otra cultura, o la poesía de Lienlaf, donde el sujeto poético entra en comunicación con los elementos de la cultura, elementos de la naturaleza, de la tierra, habla y siente por todos ellos ' "Es otra tu palabra" / me habló el copihue, / me habló la tierra(...); (...)Yo soy la visión/ de los antiguos espíritus/ que durmieron en estas pampas/. Soy el sueño de mi abuelo(... ' y también a través de la expresión de relaciones de conflicto con la cultura ajena "Bajan gritando ellos sobre los/ campos/ silvando por los esteros/ Corro a ver mi gente,/ a mi sangre,/ pero ya están tendidos sobre el suelo./ Sobre ellos pasan los winkas/ hiriendo de muerte la tierra,/ dividiendo mi corazón(...)".

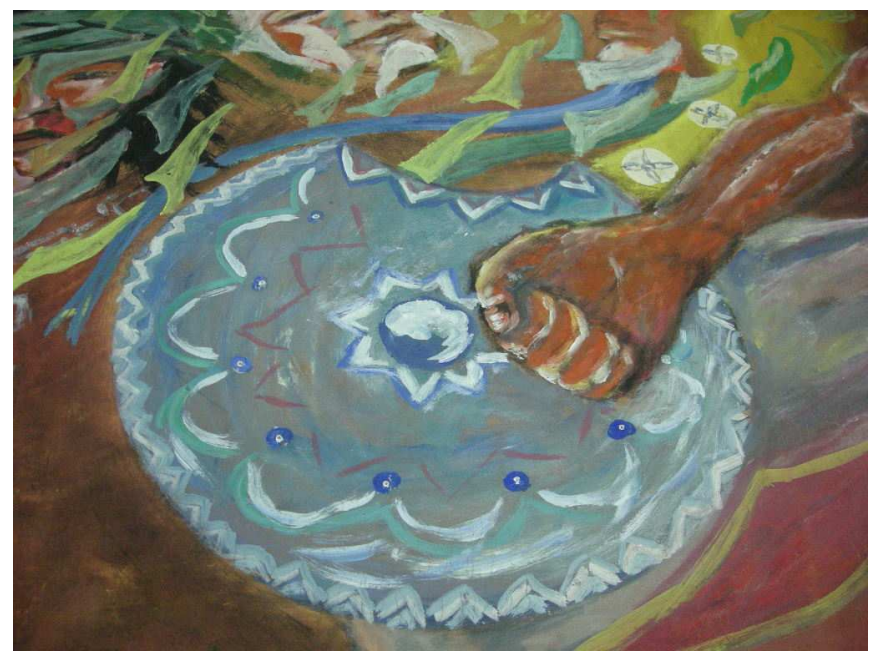

Uno y otro discurso -el poético y el visual - plasman y funden como una sola realidad la instancia subjetiva-del sujeto yo- y la expresión colectiva del mismo donde advertimos significados que evidencian a un sujeto cultural que, por una parte, asume la voz cultural y, por otra, se atribuye simbólicamente 
funciones en la cultura, valiéndose de los elementos culturales que ésta misma le ofrece; este sujeto discursivo es contingente respecto de su cultura, poetiza su sentimiento hacia ella, su proyecto de vida lo instala en el espacio textual y evidencia su relación de compromiso " (...)He corrido a rescatar/ el silencio de mi pueblo/ para guardarlo en el aliento/ que resbala sobre mi cuerpo/ latiendo(...)/ He corrido a recoger el sueño/ de mi pueblo(...)".

El sujeto cultural construye un discurso debatiente en torno a experiencias discriminadoras, racistas y violentas que resultan de las relaciones de conflicto entre culturas; en este sentido, podemos referir que la autorrepresentación y/o autoatribución del sujeto en el discurso poético y visual implica, a su vez, esa imbricada relación entre el sujeto ideológico y el sujeto cultural (Cros, 1997), siendo aquél quien realmente se autorrepresenta en el discurso, a través del sujeto cultural: "Mis manos no quisieron escribir/ las palabras/ de un profesor viejo./ (...) Mi mano/ me dijo que el mundo/ no se podía escribir"; como también este sujeto al construir ideologías (Van Dijk, 1999) construye identidad y actúa sobre los elementos simbólicos, otorgándoles significados culturales diferenciados respectos de otras culturas.

Por otra parte, el sujeto se expresa a través de variadas formas que permiten reconocer en él una construcción identitaria del yo respecto de la cultura propia - a la que no cuestiona - y, otra, diferenciada respecto de la cultura ajena -la que es cuestionada - asumiendo una posición frente a las mismas y sobre la que da cuenta en el espacio textual; los sujetos son identificados en el discurso de modo diferenciado, lo que en términos dicotómicos globalizadores identificamos como lo bueno o positivo -asociado a la cultura propia - y lo malo o negativo asociado a la cultura ajena. Esta situación se origina y sustenta en lo invadido -cultura mapuche -y lo invasor cultura occidental - “ (...) El cerro Nielol/ sentado mira/ grandes casas/ Casas que no son/ de mapuches,/ piensa (...); (...)Por el tronco caminé a través/ de cientos de generaciones/ sufriendo, riendo,/ y vi una cruz que me cortaba la/ cabeza/ y vi una espada que me bendecía/ antes de mi muerte. (...)".

Si acordamos que el lenguaje permite comprender al sujeto mediante los textos (Ricoeur, 2003), en el espacio textual poético es posible apreciar que el sujeto discursivo, además de plasmar la preocupación por la reafirmación de la identidad y la recuperación cultural, no deja de referir las relaciones de conflicto interétnico e intercultural con la otra cultura, la discriminación sufrida, la asimetría de las relaciones, la injusticia, la exclusión, el etnocidio, todas las cuales sirven de sustento al discurso del yo poético: “(..) Le sacaron la piel de la espalda/ y cortaron su cabeza./ ¡A nuestro valiente Cacique!/ y la piel de su espalda/ la usaron de bandera/ y su cabeza me la amarraron a la/ cintura". 


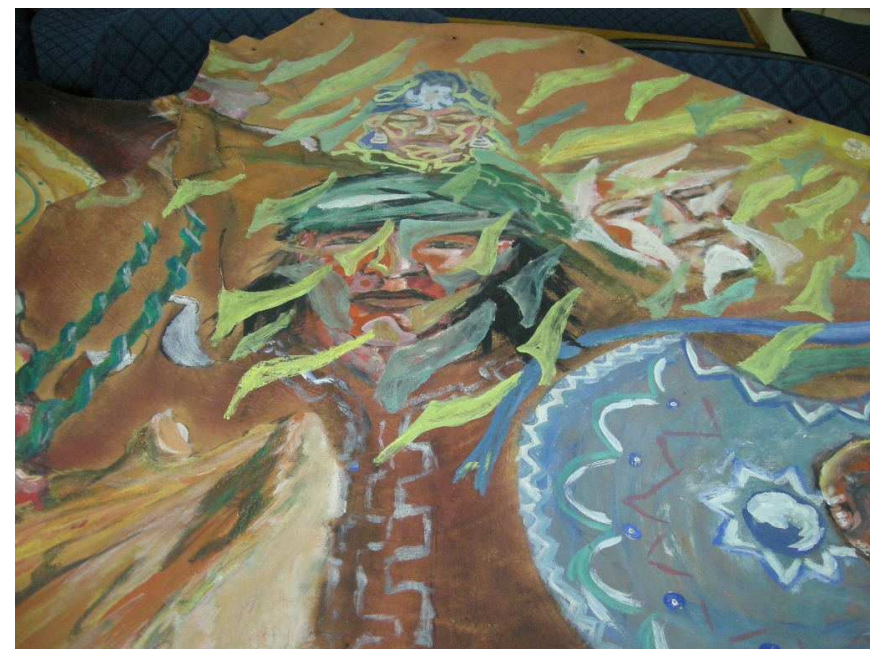

A partir de esta compleja realidad, el sujeto discursivo, tanto poético como visual, plasman en el espacio textual una línea develadora de dos culturas en contacto interétnico e intercultural conflictuado y trascendente en el tiempo; consecuentemente $\mathrm{y}$, en este mismo espacio textual, hace una defensa de la cultura propia, de su ser mapuche, dialogando al mismo tiempo con su cultura ancestral y con la sociedad mapuche, como asimismo abriéndose, a través de la expresión de aquélla, al diálogo con la cultura occidental, pero con la que no transa: esto hemos sido/esto somos/esto queremos-debemos seguir siendo.

Las acciones colonizadoras del Estado chileno sobre la sociedad mapuche y su cultura han resultado decisiva y negativamente incidentes en ellas y el discurso artístico poético y visual da cuenta de las mismas; no obstante, se orienta significativamente, hacia una línea de afianzamiento identitario a través de la reflexión, interrogación y expresión de la cultura para resistir, desde esta mirada, a la cultura mayoritaria con sus acciones de invasión, exclusión, asimilación y paternalismo, características de una cultura dominante, cuestión que puede ser superada si en la natural diferencia entre las culturas, se asume precisamente una actitud de aceptación y comprensión del ethos del otro sin pretender subsumirlo y acordar que su subjetividad se evidencia en pensamientos y acciones diferentes y, desde esta comprensión, la ontología de la diferencia (Singer,1997) pueda ser verdaderamente enunciada.

En consecuencia, esta reflexión involucrada en el espacio artístico que lleva al sujeto a penetrar en el espíritu de su cultura, a volver al tiempo pretérito, al tiempo mítico y simbólico de sus antepasados, a evocar y reconstruir prácticas culturales tradicionales, a interrogarse sobre sus ancestros, está orientado a re-definir y/o re-afirmar su identidad étnico-cultural como un modo de contestar a la otra cultura y, a la vez, ofrecer resistencia (García, 2006) a sus acciones asimilacionistas y colonizadoras. 


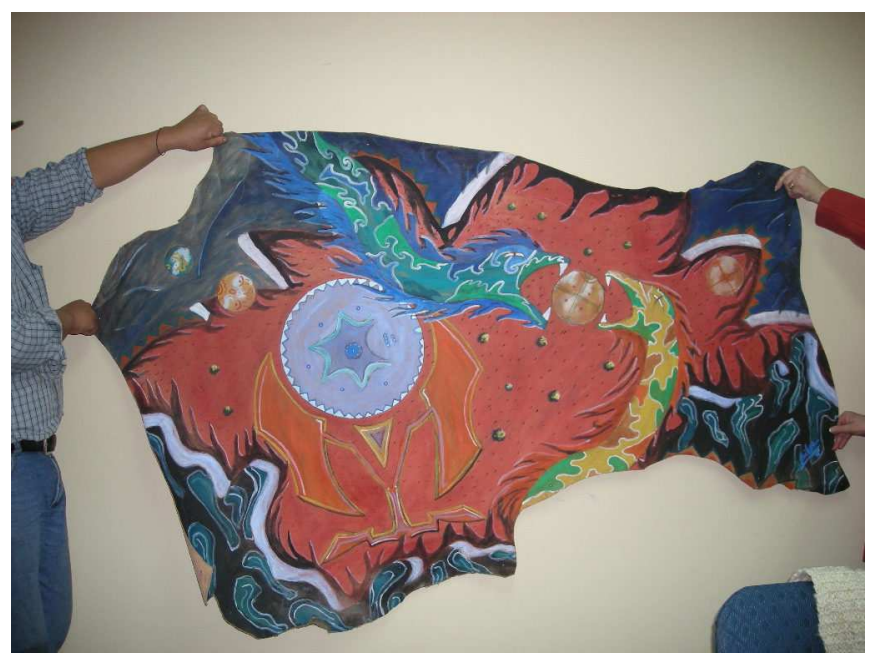

La búsqueda permanente del sujeto hacia el re-encuentro con su mismidad, origina un discurso que entra en diálogo con su ser más intimo y plasma en el espacio textual una voz cultural- su propia voz autorizada y sustentada en el conocimiento profundo de su cultura- que se autoconstruye en el discurso visual y poético. Desde ahí, entra en debate con la otra parte de su ser, la occidentalizada y ajena a quien cuestiona y re-define desde su ser mapuche, para su ser cultural: "Mis manos no quisieron escribir/ las palabras/ de un profesor viejo./ Mi mano se negó a escribir/ aquello que no me pertenecía./ Me dijo: "debes ser el silencio que nace" / Mi mano/ me dijo que el mundo/ no se podía escribir".

\section{Mismidad y otredad en el discurso}

La otredad se relaciona con la extrañeza, con una carencia de unidad del ser, una sensación de aislamiento como consecuencia de formar parte de una minoría, lo que a priori no tiene que ser necesariamente negativo; puede incluso constituir un aspecto ventajoso según cómo se enfrente. En la expresión poética y visual que estudiamos, hay un discurso de la otredad que se construye desde la mismidad del sujeto discursivo, orientada a resolver y expresar la identidad cultural; la otredad se orienta al re-encuentro con aquello que ya no se tiene, con lo que ha dejado de estar, con lo que se ha perdido; reclama al sujeto la necesaria e imprescindible acción de recuperar la pérdida, para recuperar asimismo la integridad de su ser.

Esta condición del discurso es verdaderamente interesante si la vemos en una línea de afianzamiento identitario. El discurso se constituye en expresión de la cultura, en este caso, la cultura ancestral de la sociedad mapuche y de las relaciones de tensión con la sociedad occidental, donde el sujeto del discurso evidencia las mismas con los elementos de la cultura tradicional, los apropiados de la otra cultura y transformados al modo de aquélla para elaborar un producto artístico propio.

Al respecto, debemos señalar que particularmente los artistas mapuches, como asimismo el pueblo mapuche en general, manifiestan la capacidad de incorporar elementos de la cultura con la cual han estado en contacto y además 
lo hacen únicamente con aquéllos que pueden ocupar para sus propios fines, esto es, a través de mecanismos de incorporación selectiva (Bunster,1970) que le permiten, por una parte, incorporarse en forma adecuadamente a la cultura y, por otra, reforzar su cultura tradicional.

Para evidenciar en el espacio textual la fractura de las relaciones interétnicas e interculturales, el discurso poético y visual da cuenta de sus características, proponiendo significados que reformulan la realidad construida (Berger y Luckmann, 1991) por el discurso oficial y colonizador. Para ello, recurre a la cultura propia, con todos sus elementos culturales tradicionales y va así reforzando el sentido y afianzamiento identitario como en el poema "Pasos sobre tu rostro": " (...) Soy el tronco madre/ el que arde/ en el fuego de nuestra ruka" o el poema "Rewe del pillán": "Una mano sostiene el kultrung/ como el universo sostiene/ a la tierra/ (...)". El discurso expresa un arraigo cultural, una necesidad de sentirse parte integrada y perteneciente a un espacio propio- la cultura ancestral- donde están los elementos simbólicos y las expresiones culturales que la sustentan, todo lo cual constituye la seguridad del sujeto perteneciente a ella y donde, desde allí, se desprende su identidad, elemento clave de la realidad subjetiva (Berger y Luckmann: id) y en diálogo con lo social, pues es en los procesos sociales donde esa identidad es originada.

Ésta es condición sine qua non para la existencia confiada y sana de quien forme parte de un pueblo y a partir de la cual pueda establecer y desarrollar relaciones con otros, sin sentir amenazada su identidad por la imposición de una cultura dominante. Por esto, el sujeto vuelve su mirada a la cultura propia, la enfatiza y reafirma, al mismo tiempo que re-afirma su identidad, a pesar de la cultura impuesta, y la plasma en su obra artística, no obstante, que es precisamente en los procesos sociales como señala Berger y Luckmann donde esa identidad es originada, por tanto, también es ahí donde se fortalece.

En este sentido, los procesos históricos vivenciados por la sociedad mapuche -minoritaria -respecto de la sociedad occidental -mayoritaria - y de los que da cuenta la expresión poética y visual, han posibilitado un fortalecimiento identitario con la cultura propia, la que se muestra definida y respecto de la cual el sujeto del discurso se revela resuelto a expresar.

Consecuentemente, la mismidad se nutre de esta otredad que ya no resiente como amenaza a su identidad; el sujeto cultural se estabiliza, no obstante el dinamismo de su ser y el de la otredad que se halla en permanente despliegue, y entra en armonía con su mismidad, ahora afianzada en la recuperación de un sentido de vida propio, independiente y trascendente a su contingencia individual, por lo que ahora leemos a este sujeto y su discurso en relación con el sentido construido en un acto semiótico dinámico (Landowski, 1993), desde el diálogo mismidad/otredad.

En el discurso visual y poético, la otredad se construye en el debate entre lo que el sujeto es en esencia y lo que no quiere ser; este no querer ser es lo invadido, lo invisibilizado, lo ausente; un no querer que en el discurso oficial ha mantenido suspendida y disfrazada su verdadera historia, pero que, no 
obstante, en el discurso artístico cobra vida propia y se hace voz en la mismidad del sujeto.

Por su parte, el discurso textualiza y pone en evidencia que el otro-ajeno cultural -no mapuche -, es construido a través de sus acciones colonizadoras y consecuencias ingratas respecto del sujeto mapuche. No obstante esta semantización, el discurso cobra otro sentido en un nivel más profundo del texto, cuyo principal significado es la defensa cultural de lo propio en función de resistir al discurso ajeno de la cultura occidental y el cual se torna verdaderamente significativo en el sentido global de la obra.

El discurso artístico de la poesía y de la visualidad que tiene propósitos de reafirmación de la identidad cultural y resistir ${ }^{3}$, de este modo, a la cultura ajena es una producción discursiva que, sobre la base de las relaciones tensionadas con la cultura mayoritaria en contacto, estratégicamente se nutre de ellas para afianzar su identidad y comunicarla a la cultura ajena; de este modo, propone una visualización de lo propio para distinguirse así de lo diferente con el otro cultural.

Observamos, así, un sujeto que asume un doble proceso comunicativointracultural e intercultural- a través del cual, y por una parte, se explicita la reafirmación identitaria de la cultura propia y la necesaria plasmación de la diferencia con la cultura ajena; y, por otra, la textualización de procesos interculturales complejos que contienen la negación e invisibilidad impuestas por la cultura occidental.

El sujeto textual se construye cultural e identitariamente en esta complejidad y propone un discurso artístico mediado indefectiblemente por mecanismos y recursos de hibridaje y heterogeneidad cultural, reconciliados en el espacio textual, cuestión que implica la capacidad de transformar los elementos culturales ajenos e ir dando forma y vida a un arte propio, cada vez más particular e identitario de la cultura propia (Carrasco, 1993).

Las investigaciones señalan que es posible reconocer variados discursos en el ámbito de las expresiones artístico-literarias, tanto aquéllos vinculados con prácticas tradicionales de la cultura propia, como otros relacionados con cánones discursivos de la cultura occidental (Carrasco, García, 2005:13-23).

En ambos discursos- el poético y el visual, el sujeto construye un discurso orientado a significados socio-culturales propios del mundo mapuche y revela, a la vez, la presencia de elementos de la cultura occidental con la que ha estado en contacto y en conflicto.

\footnotetext{
${ }^{3}$ Sobre el discurso poético mapuche, Mabel García lo señala como discurso de resistencia cultural a propósito de un estudio de su autoría sobre el discurso poético de Graciela Huinao, donde señala que éste tiene propósitos de actuación en el espacio de la comunicación pública, lo que lo constituye como un discurso que rebasa su condición estética.
} 


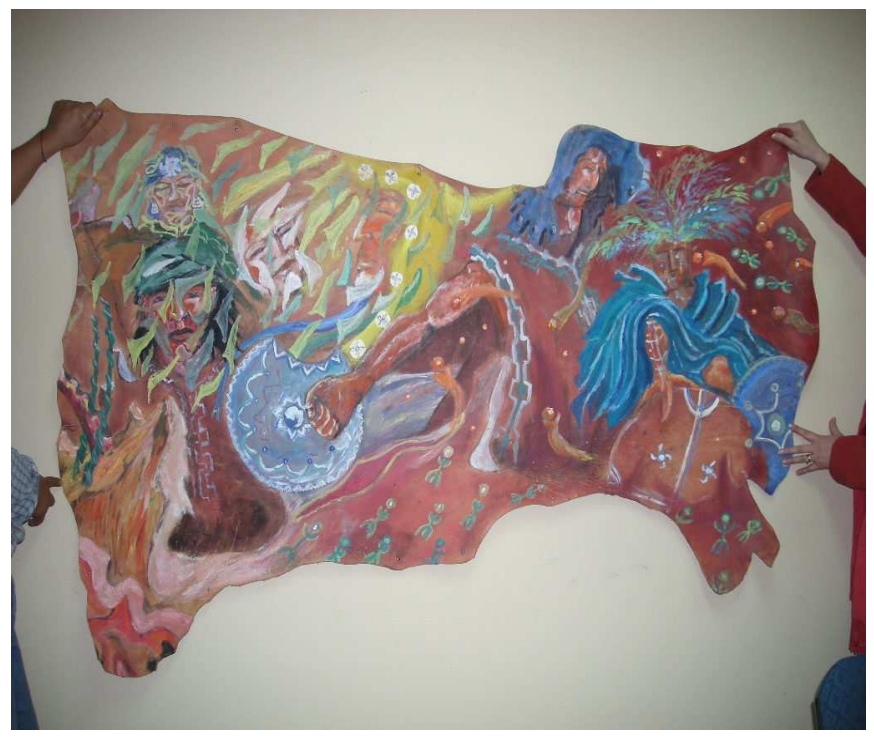

La investigadora Mabel García ( 2005) ${ }^{4}$ señala que en el actual discurso poético mapuche se pueden distinguir diferentes etapas, como textos poéticos iniciales esporádicos, de apego a la Mapu Nuke -Madre tierra -; una segunda etapa más larga y compleja contiene variados tópicos que expresan el reconocimiento y asunción de posiciones definidas y diferenciadas sobre problemáticas de identidad étnico- cultural; la tercera etapa contiene un proyecto poético e intelectual más consciente de recursos políticos y publicitarios de la expresión poética y artística en tanto discurso público.

Esta distinción nos permite observar el proceso vivido por la creación poética mapuche desde un momento en que el poeta empieza a re-conocerse como sujeto mapuche, haciéndolo desde su sentir ancestral en su relación con la tierra; posteriormente, ya con una clara definición de su identidad, enfrenta, reclama y denuncia su historia de pueblo-nación, invisibilizada por la historia oficial impuesta de la nación chilena, tiempo en el cual potencia su cultura a través de la consolidación de sus expresiones artísticas. Finalmente, evidencia una línea de reflexión sobre su hacer artístico propiamente tal y las formas de constituirse en un referente autorizado y confiable de conocimiento y expresión de su cultura: "Se ha despertado el ave de mi corazón/ extendió sus alas/ y se llevó mis sueños para abrazar la/ tierra".

Por su parte, el arte visual que no ha estado ajeno a los conflictos con la sociedad mayoritaria y al contacto interétnico e intercultural con la misma, ha mantenido un arte tradicional que involucra técnicas y elementos culturales propios, como la práctica de la pintura en cuero y el contacto con la otra cultura lo ha hecho introducir elementos culturales ajenos como la práctica de la pintura en óleo y pastel, la técnica del pirograbado e innovar con los mismos, generando prácticas artísticas interculturales que se van posicionando y afianzando en el quehacer de la creación artística nacional, pero con una

\footnotetext{
${ }^{4}$ Estas etapas las distingue a propósito de un trabajo suyo sobre traducción y resistencia cultural en el poemario Arco de Interrogaciones de Bernardo Colipán. I Congreso Latinoamericano de Antropología. Universidad Nacional de Rosario. Rosario. Argentina, 2005.
} 
propuesta que contiene rasgos específicos y diferenciadores de una expresión étnico-cultural.

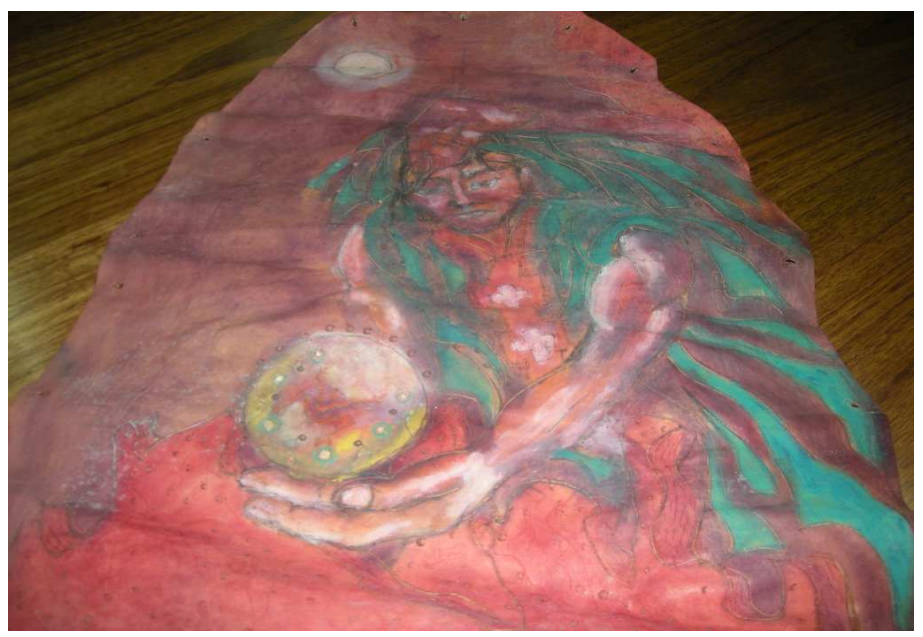

El énfasis en aspectos creenciales y cosmovisionales (García, 2005) de la cultura propia a través de la expresión de prácticas culturales y ancestrales remite a un re-posicionamiento y recuperación de la cultura, que posibilitan el afianzamiento de la identidad cultural.

La co-presencia del idioma mapudungun y español colabora con el sujeto en la construcción de un mundo en el que sentidamente da cuenta de injusticias de un pueblo contra otro, donde evidencia sentimientos de frustración, afianzamiento de la identidad y resistencia cultural, elementos que sustentan la idea de recuperación de la cultura tradicional, ayudados por la expresión del mundo de los ancestros, la cercanía y comunión con el mundo natural, el diálogo con la tierra, con su propio mundo interior, con su abuela, con sus sueños: " La pampa recogió mis huesos (...) La pampa me pidió que cantara/ la poesía del infinito/ luego me dijo que fuera/ hasta el gran fuego de las estrellas/. Me dijo que allí despertaría".

Hay muchos momentos en los que el hablante expresa su rebeldía por la injusticia sufrida por su pueblo; entonces, necesita recuperar el mundo ancestral y nutrirse de él para vivir el contacto con la otra cultura, sin tener que suspender la propia como lo ya vivido por largos siglos. En el poema "Estoy" da cuenta de su ser cultural, él es la metáfora de sus antepasados, la esperanza de su pueblo: “ (...)Voy como agua/ por este río de vida/ hacia el gran mar de lo que/ no tiene nombre/ Yo soy la visión/ de los antiguos espíritus/ que duermen en estas pampas/ Soy el sueño de mi abuelo/ que se durmió pensando/ que algún día regresaría/ a esta tierra amada/ (...)".

La escritura de Lienlaf, dice Iván Carrasco (2000:139-149), “consiste básicamente en la transcodificación de la tradición del canto indígena tradicional, pero para tratar la problemática contemporánea de los mapuches" señala que "la reflexión sobre su poesía le ha permitido darse cuenta de que existencialmente su situación es ambigua, pues oscila entre dos mundos". "Se levanta un sol violeta y lo veo,/ mis manos están azules/ y flores mojadas caen a mi lado./ (...)Mi pensamiento vaga buscándome la/ mente/ entre las 
paredes de edificios/ iluminados y fríos/ (...); Ando por otras tierras/ durmiendo/ sueño frente a una honda/ quebrada/ (...)".

Es una poesía que aborda temáticas de la tradición cultural, donde los elementos simbólico-creenciales se hacen presentes a través del mito de TrengTreng y Kai-Kai, la presencia de otros elementos culturales y/o rituales como el rewe, el kultrung, todos los cuales juegan un rol trascendente en el afianzamiento de la cultura ancestral, la que es vivenciada en un mundo complejo de relaciones de contacto con la cultura que les ha impedido históricamente vivirla. "Kai-Kai sobre su espalda/ Treng-Treng crece./ Kai-Kai se ha puesto a descansar/ en una colina con flores/ (...)".

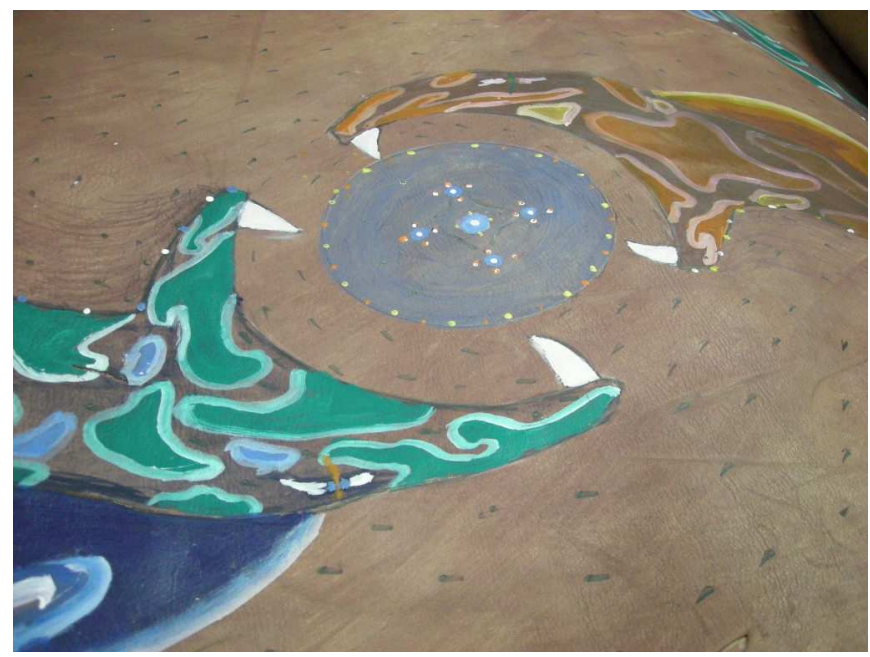

El contacto con la otra cultura no ha sido grato; es la invasión, la violencia, "Mis manos no quisieron escribir/ las palabras de un profesor viejo/ Mi mano se negó a escribir/ aquello que no me pertenecía"; o "Temucociudad/ debajo de ti/ están durmiendo/ mis antepasados"; la escritura, símbolo de lo occidental, invade al otro; Temuco-ciudad, desplazó e invadió con sus "Casas que no son/ de mapuches".

La construcción del sujeto en el discurso poético puede ser evidenciada mediante el procedimiento de intertextualidad transliteraria (Rodríguez, 1994) que permite identificar el discurso histórico mapuche, el discurso de tradición oral mapuche, el discurso mitológico, el discurso winka, el discurso cosmogónico -antropológico - estos cinco discursos presentes en Se ha despertado el ave de mi corazón, poemario relevante de Lienlaf, centran su interés temático en la denuncia y reivindicación.

El discurso histórico se refiere a prácticas de tortura y muerte por parte de los winkas en contra del pueblo mapuche- poema "Le sacaron la piel": "Tres veces vino el malón/ tres veces lo rechazamos/ pero ahora viene otra vez/ y no podemos luchar./ El winka está disparando/ (...)"; también este discurso se da en la referencia a héroes- Lautaro, por ejemplo: “(...) Lautaro viene a buscarme,/ a buscar a su gente/ para luchar con el espíritu/ y el canto/(...)"; y cuando alude a las consecuencias de la colonización- poema "Temuco-Ciudad": “El río Cautín/ en el medio/ baja llorando/ por Temuco/ llora/ (...)". 
La estructura dialógica en algunos poemas da cuenta del discurso de tradición oral, como el poema Palabras dichas, asimismo con los referentes naturales, culturales y geográficos presentes en los textos. " "Es otra tu palabra" / me habló el copihue,/ me habló la tierra./ Casi lloré./ "Tus lágrimas debes / dársela a las flores" / me habló el pájaro chucao.'

El discurso cosmológico da cuenta de la cosmovisión mapuche, de lo sagrado, poema "Rehue del Pillán", que alude a elementos rituales propios; el discurso winka contiene elementos de la cultura winka, conceptos que evidencian el contacto entre ambas culturas y la influencia de la cultura mayoritaria; y el discurso mitológico que incorpora de modo importante sucesos, elementos o seres mitológicos, como el poema "El sueño de Mankean": “(...) Cerca de la madre de las aguas/ me miró la piedra en flor/ y en el choque incesante de las olas/ me abrazó su espíritu/ (...)."

Estos discursos funcionan como estrategias de expresión de la identidad mapuche a través de una fusión y diálogo de los elementos culturales propios y de los apropiados de la cultura.; no obstante respecto de la función y significados globales de estos discursos, los advertimos como estrategias de afianzamiento identitario y visibilización cultural, que en el espacio textual son re-significados en una línea de re-posicionamiento de la cultura y sociedad mapuches respecto de la sociedad global y, a la vez, como un modo válido de oponerse discursivamente a ésta.: "El sueño de la tierra/ grita/ en mi corazón..."

Sin embargo, y como es natural entre culturas que viven en contacto, el poeta Leonel Lienlaf expresa en su obra una orientación hacia la búsqueda de diversas propuestas que evidencian la adopción del canon de la poesía occidental, no obstante tener un proyecto escritural propio, como asimismo, el artista plástico Juan Silva Painequeo, quien asume prácticas tradicionales en su pintura en cuero; pero, por otra parte, a través de la pintura mural en espacios públicos y la pintura en óleo y pastel, asume técnicas de la cultura occidental. (Carrasco, García, 2005).

Un sentido y propósito de la obra de este artista plástico es recuperar la cultura tradicional, afianzar la identidad mapuche, recreando la historia ancestral, el mundo mítico-creencial de los antepasados de su pueblo, sus formas de organización, el sistema de normas.

Su obra expresa en el espacio artístico creado por el sujeto del discurso visual la organización del pueblo mapuche, específicamente la organización político-administrativa de la sociedad mapuche, aspecto relevante en la recuperación de la armonía con el mundo ancestral y el afianzamiento de la cosmovisión de la cultura. 


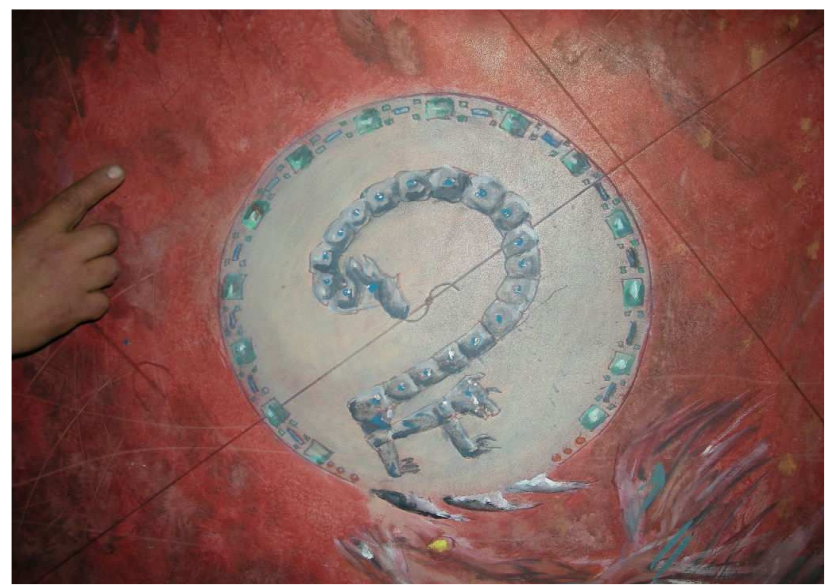

Para todo esto es necesario volver permanentemente la mirada al pasado, al tiempo primordial, al tiempo circular del mundo mítico-creencial donde nace y se acuna la identidad del sujeto, la que recurrentemente se nutre de ese tiempo-espacio simbólico al trancurrir el tiempo histórico en el que se expresa, transita e interactúa.

Destacan, entre otros símbolos como el pehuen- antiguo guerrero mapuche- prácticas, elementos culturales, héroes o toquis como Lautaro o Lefxaru, poderes ancestrales, como el poder de la machi que se expresa en el kultrun o el machi kimun que refiere el conocimiento de la machi, símbolos plasmados en el espacio artístico-visual.

Un ser mítico importante es el Choike - avestruz - al que Hugo Carrasco (2005) sitúa en el conjunto textual plástico de Silva Painequeo en torno al núcleo Trentren y Kaikai; como asimismo, la presencia del weichafe que es esencial en la lucha del pueblo mapuche, el arte visual de Silva Painequeo lo actualiza permanentemente; por otra parte, el rewe y el kultrun, como elementos de la cultura, son también permanentemente aludidos en su creación artística .

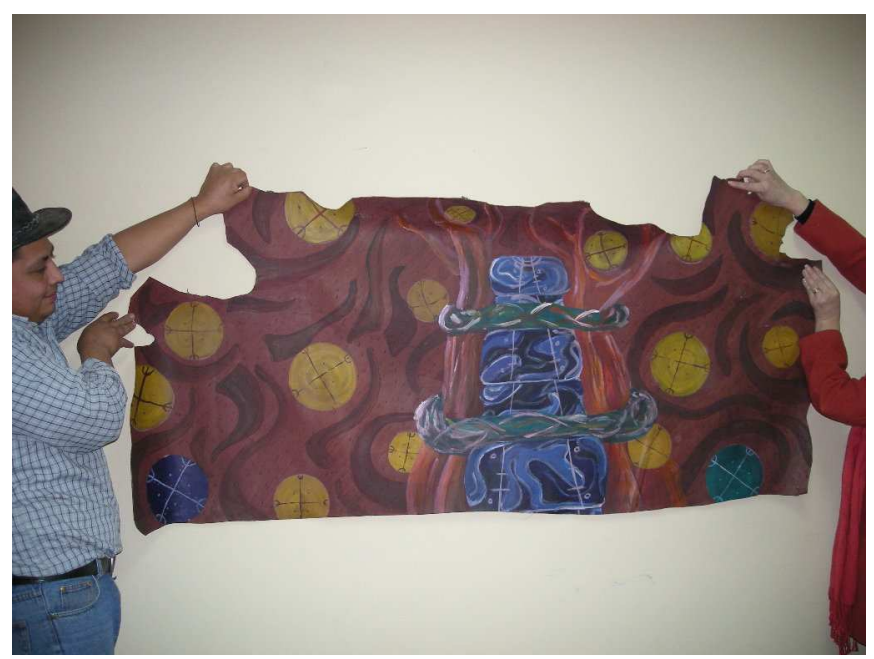

Esencialmente, en el discurso visual el sujeto se construye a través del mundo mítico-creencial y mundo ancestral, fundamentalmente, de donde se fortalece y genera su discurso visual, expresado por ejemplo, en el origen del mundo mapuche con Treng-Treng y Kai-Kai. 
Por otra parte, este sujeto discursivo visual construye al otro cultural a través de la expresión del contacto interétnico e intercultural conflictuado, otorgándole significados consecuentes con una línea colonizadora que ha ejercido poder $y$, con él, ha provocado una suspensión en la expresión genuina de la cultura mapuche, la que ahora es potenciada en el arte visual.

A través del tiempo ha existido un discurso colonizador que ha asumido la voz del otro, desplazándolo, hablando por él y sobre su discurso (García, 2006) y el discurso de este otro que refiere su ser cultural no ha salido del ámbito de su cultura, manteniéndose, por tanto, la posición desigual de uno respecto del otro. Esta condición es apoyada por un discurso desvirtuado sobre la otredad que representa la mirada del sesgo cultural del colono, por lo que superar esta condición discursiva ha resultado dificultosa, sobre todo si su superación o decir desde los pueblos originarios (García, 1996) pasa por mecanismos, tiempos y espacios legitimados políticamente por la cultura predominante.

En este sentido, el sujeto poético y visual textualiza un discurso propio con el que habla de sí, para sí, pero también habla para los otros y sobre los otros, traspasando el espacio textual de la cultura propia y posicionándose legítimamente en un espacio de validación desde la cultura propia y desde la cultura ajena.

Fundamentalmente, el sujeto poético y visual se constituye en una voz que expresa el contacto forzado y las tensas relaciones con la cultura occidental, a la cual enfrenta discursivamente expresando la cultura tradicional mapuche y en este espacio textual de re-creación del discurso, también re-construye y reafirma su identidad cultural, en palabras de Landowski (1993:70): "se trata de construir la propia identidad construyendo la alteridad", al mismo tiempo que establece diferencias con la cultura global para crear y proponer un arte distintivo y propio.

\section{Algunas consideraciones finales}

El arte poético y visual mapuche en Leonel Lienlaf y Juan Silva Painequeo, respectivamente, se halla conectado a través de las temáticas relacionadas con la historia conflictuada con la sociedad occidental, siendo éste un referente importante en estas expresiones artísticas. No obstante, destaca en ellos la temática de lo propio cultural, una orientación a expresar el mundo mapuche, su identidad, su ser cultural, su cosmovisión.

Dentro de este contexto, el sujeto cultural mapuche es construido en el discurso a través de la plasmación y visibilización de los elementos culturales propios, fundamentalmente de aquéllos que le permiten distinguirse de la cultura ajena y los que se ubican en un espacio mítico-creencial, en la religión, en el mundo ancestral. Como asimismo, en el discurso se construye el otro cultural sobre la base de las relaciones de conflicto generadas en el permanente y forzado contacto con la otra cultura.

Si bien ambos creadores expresan la cultura mapuche, el arte visual y poético involucra la cultura occidental, de la cual naturalmente toma elementos culturales que son innovados, logrando con ellos una identidad propia. 
No obstante, ser un sujeto desgarrado por la suspensión e invisibilidad de su historia es ser un sujeto que procura la armonía y conciliación de su ser mapuche en el re-encuentro con la propia cultura.

La otredad se re-significa y se incorpora a través del diálogo con la mismidad, expresando a un sujeto íntegro en su ser cultural el que se halla definido en su identidad; desde esta definición se expresa en el espacio textual, donde genera un discurso desde la certeza de la identidad que le permite resistir la imposición colonizante y re-posicionar su cultura frente al otro cultural.

El afianzamiento identitario evidenciado en el discurso poético y visual, perfila otro discurso, subyacente y significativo, relacionado con significados de re-posicionamiento cultural respecto de la cultura global, lo que, a su vez, hace sentido con la propuesta de García $(2003,2005,2006)$ sobre el discurso poético mapuche como discurso de resistencia cultural.

Consecuentemente, el discurso poético de Leonel Lienlaf y el discurso visual de Juan Silva Painequeo se orientan a propósitos y significados empíricos relacionados con un posicionamiento en el espacio público; un discurso que, en este sentido, reclama ser validado desde los mismos parámetros que existen en este espacio.

\section{BIBLIOGRAFÍA}

BERGER, P. y LUCKMANN, T. (1991): La construcción social de la realidad, Amorrortu editores S.A Buenos Aires-Argentina.

BONFIL, G.(1989): “La teoría del control cultural en el estudio de los procesos étnicos" en Revista Papeles de la Casa Chata Año 2, N³, México.

BHABHA, H.(2002): El lugar de la cultura, Manatial. Buenos Aires- Argentina.

BUNSTER, X. (1970): “Algunas consideraciones en torno a la dependencia cultural y al cambio entre los mapuches, Segunda Semana Indigenista ${ }_{L}$ Temuco, Ediciones Universitarias de La Frontera. 11-27

CARRASCO, H. (2005): "Juan Silva Painequeo: Búsqueda y encuentro de la "normativa" creencial" en Crítica situada. El estado actual del arte y la poesía Mapuche Editorial Florencia Temuco-Chile. 189-198

CARRASCO, H. (1993): "Poesía mapuche actual: de la apropiación hacia la innovación cultural". Revista Chilena de Literatura 43: 75-87.

CARRASCO, H. (2002): "Rasgos identitarios de la poesía chilena actual". Revista chilena de literatura $N^{\circ} 61$ : 83-110 Universidad de Chile.

CARRASCO, I. (2000): "Poetas mapuches en la literatura chilena" Estudios Filológicos $N^{\circ} 35$ : 139-149 Universidad Austral de Chile, Valdivia.

CARRASCO, H., CONTRERAS, V. y GARCÍA, M. (Ed.) (2005): Crítica situada. El estado actual del arte y la poesía Mapuche. Rakisuam.Pu mapuce tañi kimon ka tañi vl zugu fahtepu. Universidad de La Frontera, Editorial Florencia. Temuco-Chile.

CARRASCO, H. y GARCÍA, M. (2005): “Interrogantes y estado actual del arte y la poesía mapuche" en Crítica situada. El estado actual del arte y la poesía Mapuche. Rakisuam.Pu mapuce tañi kimon ka tañi vl zugu fahtepu. Universidad de La Frontera, Editorial Florencia. Temuco -Chile. 13-23. 
CROS, E. (1997): El sujeto cultural. Sociocrítica y psicoanálisis. Buenos Aires Ediciones Corregidor.

GARCÍA, M. (2005): "Mirando hacia dentro: las raíces mapuche" en Crítica situada. El estado actual del arte y la poesía Mapuche Rakisuam.Pu mapuce tañi kimon ka tañi ol zugu fahtepu. Editorial Florencia. Temuco-Chile. 133142.

GARCÍA, M. (2005): “Eduardo Rapimán. El arte como recuperación y resistencia cultural" en Crítica situada. El estado actual del arte y la poesía Mapuche Rakisuam.Pu mapuce tañi kimon ka tañi vl zugu fahtepu. Editorial Florencia. Temuco-Chile. 199-211.

GARCÍA, M. (2005): Lenguaje, traducción y resistencia cultural en el discurso poético mapuche: "Arco de interrogaciones" de Bernardo Colipán. I Congreso Latinoamericano de Antropología. Universidad Nacional de Rosario. Rosario-Argentina.

GARCÍA, M. (2006) :"El discurso poético mapuche y su vinculación con los "temas de resistencia cultural". Revista Chilena de Literatura, $N^{\circ} 68$ : 169197. Universidad de Chile.

GARCÍA, M (2003): “El discurso poético mapuche de Graciela Huinao. Las condiciones de la emisión asociadas a la narración". XV Congreso de La Sociedad Chilena de Lingüística. Universidad Metropolitana de Ciencias de la Educación. Santiago- Chile.

LANDOWSKI, E. (1993): La sociedad figurada Ensayos de sociosemiótica Universidad Autónoma de Puebla Fondo de Cultura Económica México.

RICOEUR, P. (2003): El conflicto de las interpretaciones, B. Aires FCE.

RODRÍGUEZ, C. (1994): Leonel Lienlaf: La voz de la bandada. Enfoque etnocultural sobre el texto "Se ha despertado el ave de mi corazón". Tesis de Magíster Universidad Austral de Chile, Valdivia.

SINGER, P. (1997): Repensando la vida y la muerte. El derrumbe de nuestra ética tradicional. Paidós, Barcelona.

\section{TEXTO FUNDAMENTAL}

LIENLAF, L. (1989): Se ha despertado el ave de mi corazón, Editorial Universitaria S. A. 